\title{
The Relation between Frequency of E-Cigarette Use and Frequency and Intensity of Cigarette Smoking among South Korean Adolescents
}

\author{
Jung Ah Lee ${ }^{1}$, Sungkyu Lee ${ }^{2}$ and Hong-Jun Cho ${ }^{1, *}$ \\ 1 Department of Family Medicine, ASAN Medical Center, University of Ulsan College of Medicine, \\ Seoul 05505, Korea; junga_lee@amc.seoul.kr \\ 2 National Evidence-Based Healthcare Collaborating Agency, Seoul 100705, Korea; wwwvince77@gmail.com \\ * Correspondence: hjcho@amc.seoul.kr; Tel.: +82-2-3010-3812; Fax: +82-2-3010-3815
}

Academic Editor: Steven Y. Sussman

Received: 27 October 2016; Accepted: 10 March 2017; Published: 14 March 2017

\begin{abstract}
Introduction: The prevalence of adolescent electronic cigarette (e-cigarette) use has increased in most countries. This study aims to determine the relation between the frequency of e-cigarette use and the frequency and intensity of cigarette smoking. Additionally, the study evaluates the association between the reasons for e-cigarette use and the frequency of its use. Materials and Methods: Using the 2015 Korean Youth Risk Behavior Web-Based Survey, we included 6655 adolescents with an experience of e-cigarette use who were middle and high school students aged 13-18 years. We compared smoking experience, the frequency and intensity of cigarette smoking, and the relation between the reasons for e-cigarette uses and the frequency of e-cigarette use. Results: The prevalence of e-cigarette ever and current (past 30 days) users were $10.1 \%$ and $3.9 \%$, respectively. Of the ever users, approximately $60 \%$ used e-cigarettes not within 1 month. On the other hand, $8.1 \%$ used e-cigarettes daily. The frequent and intensive cigarette smoking was associated with frequent e-cigarette uses. The percentage of frequent e-cigarette users ( $\geq 10$ days/month) was 3.5\% in adolescents who did not smoke within a month, but $28.7 \%$ among daily smokers. Additionally, it was $9.1 \%$ in smokers who smoked less than 1 cigarette/month, but $55.1 \%$ in smokers who smoked $\geq 20$ cigarettes/day. The most common reason for e-cigarette use was curiosity ( $22.9 \%)$, followed by the belief that they are less harmful than conventional cigarettes $(18.9 \%)$, the desire to quit smoking $(13.1 \%)$, and the capacity for indoor use $(10.7 \%)$. Curiosity was the most common reason among less frequent e-cigarette users; however, the desire to quit smoking and the capacity for indoor use were the most common reasons among more frequent users. Conclusions: Results showed a positive relation between frequency or intensity of conventional cigarette smoking and the frequency of e-cigarette use among Korean adolescents, and frequency of e-cigarette use differed according to the reason for the use of e-cigarettes.
\end{abstract}

Keywords: electronic cigarette; e-cigarette; smoking; adolescent; frequency; tobacco

\section{Introduction}

The electronic cigarette (e-cigarette) is a battery-operated device that vaporizes a solution of nicotine, glycerol, and flavoring agents [1]. It is often advertised as a healthier alternative to conventional cigarettes or as a smoking cessation aid [1,2]. The prevalence of e-cigarette use among adolescents has been increasing in many countries [3-7]. Several studies have found that adolescents who used only e-cigarettes were more likely to initiate the use of combustible cigarettes later [8-12].

Current e-cigarette users are defined as adults and adolescents who have used them once or more during the past 30 days. It is important to distinguish established users from non-established 
users because there is a difference in the reason for e-cigarette initiation in addition to the extent of its use [13]. According to previous studies considering current cigarette smokers, the successful smoking cessation rate was higher among daily or intensive e-cigarette users compared with non-daily or intermittent users [14-16].

The general concept of current e-cigarette use is broadly defined to differentiate experimenters from regular users. Studies have argued that most adolescent e-cigarette users are experimenters and only conventional cigarette smokers tend to use e-cigarettes on a regular basis [17]. A recent study on the distribution of the frequency of e-cigarette use among adults tried to define regular users among current adult smokers and suggested more than 5 out of the past 30 days as a definition of a "persistent user" [13]. Only a few studies have reported that the frequency of e-cigarette use was particularly associated with conventional cigarette smoking among adolescents. Warner demonstrated that, even though e-cigarette use frequency rose with the amount of ever smoking in US adolescents, the frequency of e-cigarette use was not associated with the amount of conventional cigarette smoking [18].

It is important to recognize the reasons for e-cigarette initiation of adolescents because it can help us better understand what attracts adolescents to e-cigarettes. Furthermore, several reasons for initiating e-cigarettes may have increased the risk of continued use of e-cigarettes [19]. A study has reported that the reasons for e-cigarette use were related to future smoking cessation among adults [20]. Smokers who used e-cigarettes for smoking cessation showed a higher smoking cessation rate, whereas those with other reasons showed lower smoking cessation rates than non-e-cigarette users [20]. Some studies have reported predictors of continued e-cigarette use [19] and the reasons for experimentation among adolescents [21]; however, few have investigated the reasons for initiation regarding the intensity of e-cigarette use. This study aims to determine the relation between the frequency of e-cigarette use and the frequency and intensity of conventional cigarette smoking among Korean adolescents based on a nationally representative cross-sectional sample. In addition, the study identifies the association between the reasons for e-cigarette use and the frequency of its use.

\section{Materials and Methods}

\subsection{Survey Overview and Study Participants}

The Korean Youth Risk Behavior Web-Based Survey (KYRBWS) is a nationally representative cross-sectional survey of Korean middle and high school students. The KYRBWS was established in 2005 for assessing health-risk behaviors of adolescents and has provided data for the development and evaluation of school health policies and programs in Korea. The survey was approved by the institutional review board of the Korea Centers for Disease Control and Prevention (2014-06EXP-02-P-A). Written informed consent was received from all participants and their parents or legal guardians. The KYRBWS was described in detail in a previous study [22]. In brief, the KYRBWS data were collected anonymously using a multistage, stratified, cluster-sampling method. The stratification was performed on the basis of 44 provinces and types of schools according to geographic accessibility, the number of schools and population, living environment, smoking rate, and alcohol consumption. The 2015 survey included 70,362 students (ages 13-18 years) in 2400 classrooms (secondary sampling units), which included three classes considering the three year school-term (one class for each year) from each of 400 middle schools and 400 high schools (primary sampling units). Of these, 68,043 adolescents from 797 schools participated in the survey ( $96.7 \%$ response rate). From these participants, we analyzed 6656 adolescents who had an e-cigarette experience. Our study is based on the public use dataset (https://yhs.cdc.go.kr/new/pages/main.asp). 


\subsection{Measures}

\subsubsection{Predictor Variables}

Ever conventional cigarette smokers were defined as those who responded "yes" to the question, "Have you ever tried a cigarette, even one puff, in your life?" Among ever-smokers, current conventional smokers were defined as those who replied from " 1 and 2 days" to "every day" for the question, "During the past 30 days, how many days did you smoke cigarettes, even one cigarette?" Intensity of conventional cigarette smoking was defined by the following question: "How many cigarettes did you smoke a day on average in the past 30 days?" Response options were "fewer than 1 per day," "1 per day," " 2 to 5 per day," " 6 to 9 per day," "10 to 19 per day," and "20 or more per day."

The reasons for e-cigarette use were collected from the following question: "Which of the following is your main reason for using e-cigarettes?" Response options were "it seems to be less harmful," "for smoking cessation," "for indoor use," "it is easy to obtain," "it tastes better," "it has a good flavor," "it does not smell like tobacco," "curiosity," and "other."

We included several sociodemographic variables, such as age, gender, and school grade that might be associated with conventional cigarette smoking or e-cigarette use.

\subsubsection{Outcome Variable}

Ever e-cigarette use was defined by a "yes" answer to the following question: "Have you ever tried e-cigarettes?" Current e-cigarette use was defined as those who replied from " 1 and 2 days" to "every day" to the question, "During the past 30 days, how many days did you use e-cigarettes?" The number of days that used e-cigarette was re-grouped into 0-2 days/month, 3-9 days/month, and $\geq 10$ days/month.

\subsection{Statistical Analysis}

All data were analyzed by considering both sample weights and the complex sample design of the survey. The number of participants was presented as unweighted samples of individuals who participated in the KYRBWS 2015 survey. The prevalence of demographic characteristics and e-cigarette use was presented on the basis of the weighted percentage of participants with $95 \%$ confidence intervals to represent Korean adolescents. The chi-square test was used for categorical variables. A threshold for statistical significance was set at a two-tailed $p<0.05$ level. All data were analyzed using SPSS version 21.0 (SPSS Statistics Inc., Chicago, IL, USA).

\section{Results}

\subsection{General Characteristics of the Study Subjects}

Table 1 shows the sociodemographic characteristics and the health-risk behaviors for all participants in the 2015 KYRBWS, with $52.1 \%$ being boys and $48 \%$ being girls. The prevalence of ever conventional cigarette smokers was $17.1 \%$, and $3.7 \%$ of participants were current daily conventional cigarette smokers. Among the participants, $9.6 \%$ had not smoked cigarettes in the last month, although they were ever conventional cigarette smokers. Additionally, $1.3 \%$ of participants had smoked conventional cigarettes only for 1-2 days within month. The prevalence of ever and current e-cigarette use was $10.1 \%$ and $3.9 \%$, respectively. Out of the total participants, $6.0 \%$ were ever e-cigarette users but had not used e-cigarettes within a month, while $1.3 \%$ had used them for only 1-2 days per month. Daily e-cigarette users were $0.7 \%$. 
Table 1. Sociodemographic and smoking-related characteristics of participants $(N=68,043)$.

\begin{tabular}{|c|c|c|c|c|}
\hline \multicolumn{2}{|c|}{ Characteristics } & \multirow{2}{*}{$\frac{N}{67,671}$} & \multirow{2}{*}{$\begin{array}{c}\text { Unweighted, \% } \\
14.96 \pm 1.74\end{array}$} & \multirow{2}{*}{$\begin{array}{c}\text { Weighted, \% (SE) } \\
15.09 \pm 0.02\end{array}$} \\
\hline Age (years) & Mean \pm SE & & & \\
\hline \multirow{6}{*}{ Grade } & 7 & 10,786 & 15.9 & $13.7(0.3)$ \\
\hline & 8 & 11,442 & 16.8 & $15.6(0.3)$ \\
\hline & 9 & 12,071 & 17.7 & $17.7(0.3)$ \\
\hline & 10 & 11,122 & 16.3 & $17.4(0.3)$ \\
\hline & 11 & 11,113 & 16.3 & $17.6(0.3)$ \\
\hline & 12 & 11,509 & 16.9 & $18.1(0.3)$ \\
\hline \multirow{2}{*}{ Sex } & Boy & 35,204 & 51.7 & $52.1(1.4)$ \\
\hline & Girl & 32,839 & 48.3 & $47.9(1.4)$ \\
\hline \multirow{2}{*}{ Smoking experience } & No & 56,415 & 82.9 & $82.6(0.4)$ \\
\hline & Yes & 11,628 & 17.1 & $17.4(0.4)$ \\
\hline \multirow{8}{*}{ Smoking within 1 month } & Nonsmoker & 56,415 & 82.9 & $82.6(0.4)$ \\
\hline & Not within 1 month & 6505 & 9.6 & $9.7(0.2)$ \\
\hline & 1-2 days/month & 872 & 1.3 & $1.3(0.1)$ \\
\hline & 3-5 days/month & 403 & 0.6 & $0.6(0.0)$ \\
\hline & 6-9 days/month & 340 & 0.5 & $0.5(0.0)$ \\
\hline & 10-19 days/month & 497 & 0.7 & $0.8(0.0)$ \\
\hline & 20-29 days/month & 502 & 0.7 & $0.8(0.0)$ \\
\hline & Daily & 2509 & 3.7 & $3.8(0.2)$ \\
\hline \multirow{2}{*}{ E-cig experience } & No & 61,387 & 90.2 & $89.9(0.3)$ \\
\hline & Yes & 6656 & 9.8 & $10.1(0.3)$ \\
\hline \multirow{8}{*}{ E-cig use within 1 month } & Nonuser & 61,387 & 90.2 & $89.9(0.3)$ \\
\hline & Not within 1 month & 4090 & 6.0 & $6.1(0.2)$ \\
\hline & 1-2 days/month & 873 & 1.3 & $1.3(0.1)$ \\
\hline & 3-5 days/month & 390 & 0.6 & $0.6(0.0)$ \\
\hline & 6-9 days/month & 279 & 0.4 & $0.4(0.0)$ \\
\hline & 10-19 days/month & 323 & 0.5 & $0.5(0.0)$ \\
\hline & 20-29 days/month & 196 & 0.3 & $0.3(0.0)$ \\
\hline & Daily & 505 & 0.7 & $0.8(0.1)$ \\
\hline
\end{tabular}

SE: Standard error.

\subsection{Frequency of E-Cigarette Use According to Smoking Behaviors among Ever E-Cigarette Users}

Out of ever e-cigarette users, approximately 60\% used e-cigarettes not within 1 month. Otherwise, $16.1 \%$ used them for more than 10 days per month (Table 2). Compared with e-cigarette users for 0-2 per month, frequent users were older (16.2 years vs. 15.8 years) and were more prevalent among 12th graders than 7 th graders $(21.9 \%$ vs. $9.7 \%)$. Current use of e-cigarettes was more prevalent among ever conventional cigarette smokers (41.5\%) than among never conventional cigarette smokers (25.3\%), and e-cigarette users for more than 10/month were 2 times more prevalent among ever smokers than among never smokers (17.2\% vs. 9.5\%). A positive correlation was observed between the frequency of conventional cigarette smoking and the frequency of e-cigarette use. Percentage of frequent e-cigarette use was 9 times greater among daily smokers than among conventional cigarette users for $<1$ per month (28.7\% vs. $3.5 \%)$. Smoking amount was also positively correlated to the frequency of e-cigarette use. Frequent e-cigarette use was 6 times more prevalent among smokers going for $\geq 20$ cigarettes/day than among smokers going for $<1$ cigarettes/month (55.1\% vs. 9.1\%). 
Table 2. Frequency of e-cigarette use according to smoking behaviors among ever e-cigarette users of Korean adolescents $(N=6656)$.

\begin{tabular}{|c|c|c|c|c|c|}
\hline \multirow{2}{*}{\multicolumn{2}{|c|}{ Characteristics }} & \multicolumn{4}{|c|}{ Number of Days Used E-Cigarettes per Month $(\%, 95 \% \mathrm{CI})$ * } \\
\hline & & \multirow{2}{*}{$\begin{array}{c}0-2 \\
4962(73.7)\end{array}$} & \multirow{2}{*}{$\frac{3-9}{669(10.2)}$} & \multirow{2}{*}{$\begin{array}{c}\geq 10 \\
1024(16.1)\end{array}$} & \multirow{2}{*}{$p$-Value } \\
\hline Total & $N(\%)^{\dagger}$ & & & & \\
\hline Age (years) & Mean (SE) & $15.80 \pm 0.03$ & $15.96 \pm 0.07$ & $16.22 \pm 0.06$ & $<0.001$ \\
\hline \multirow{6}{*}{ Grade } & 7 & $84.9(79.1-89.3)$ & $5.4(3.2-9.1)$ & $9.7(6.3-14.6)$ & \multirow{6}{*}{$<0.001$} \\
\hline & 8 & 75.6 (71.1-79.5) & $11.2(8.6-14.6)$ & $13.2(10.5-16.4)$ & \\
\hline & 9 & $77.3(74.3-80.1)$ & $8.7(6.9-10.9)$ & $14.0(12.0-16.3)$ & \\
\hline & 10 & 74.9 (71.9-77.7) & $10.0(8.4-11.9)$ & $15.1(12.9-17.7)$ & \\
\hline & 11 & $75.4(72.8-77.8)$ & $10.7(9.2-12.6)$ & $13.9(12.0-16.0)$ & \\
\hline & 12 & $67.3(63.5-70.9)$ & $10.8(9.0-12.9)$ & $21.9(19.2-24.8)$ & \\
\hline \multirow{2}{*}{ Sex } & Boys & $73.5(71.8-75.2)$ & $10.2(9.3-11.2)$ & $16.3(15.0-17.7)$ & \multirow[b]{2}{*}{0.866} \\
\hline & Girls & $74.3(70.9-77.4)$ & $10.2(8.4-12.3)$ & $15.5(13.0-18.4)$ & \\
\hline \multirow{2}{*}{ Smoking experience } & No & $85.3(82.5-87.7)$ & $5.2(3.8-7.1)$ & $9.5(7.6-11.9)$ & \multirow[b]{2}{*}{$<0.001$} \\
\hline & Yes & $71.9(70.2-73.5)$ & $11.0(10.0-12.0)$ & $17.2(15.9-18.5)$ & \\
\hline \multirow{8}{*}{$\begin{array}{l}\text { Smoking within } 1 \\
\text { month (days/month) }\end{array}$} & Nonsmoker & $85.3(82.5-87.7)$ & $5.2(3.8-7.1)$ & $9.5(7.6-11.9)$ & \multirow{8}{*}{$<0.001$} \\
\hline & Not within 1 month & $92.6(91.2-93.8)$ & $3.9(3.0-5.0)$ & $3.5(2.7-4.5)$ & \\
\hline & $1-2$ & $81.0(76.8-84.6)$ & $11.1(8.4-14.7)$ & $7.8(5.5-11.1)$ & \\
\hline & $3-5$ & $66.5(59.4-72.9)$ & $19.4(14.6-25.3)$ & $14.1(9.6-20.3)$ & \\
\hline & $6-9$ & $62.7(55.3-69.5)$ & $19.3(14.2-25.8)$ & $17.9(13.1-24.1)$ & \\
\hline & $10-19$ & $55.7(50.3-61.0)$ & $18.0(14.0-23.0)$ & $26.2(21.4-31.8)$ & \\
\hline & $20-29$ & $55.8(49.6-61.9)$ & $16.6(12.8-21.4)$ & $27.5(22.7-33.0)$ & \\
\hline & Daily & $57.8(55.1-60.5)$ & $13.5(12.0-15.1)$ & $28.7(26.3-31.2)$ & \\
\hline \multirow{7}{*}{$\begin{array}{l}\text { Smoking Amount } \\
\text { within } 1 \text { month } \\
\text { (cigarettes/day) }\end{array}$} & None & $90.4(89.0-91.5)$ & $4.3(3.5-5.2)$ & $5.4(4.5-6.3)$ & \multirow{7}{*}{$<0.001$} \\
\hline & $<1$ & $81.6(77.2-85.3)$ & $9.4(6.8-12.8)$ & $9.1(6.5-12.6)$ & \\
\hline & 1 & $74.7(68.3-80.2)$ & $10.4(7.2-14.8)$ & $14.9(10.7-20.3)$ & \\
\hline & $2-5$ & $64.9(61.6-68.1)$ & $14.6(12.5-16.9)$ & $20.5(18.0-23.2)$ & \\
\hline & $6-9$ & $57.6(54.1-61.1)$ & $16.0(13.9-18.5)$ & $26.3(23.2-29.7)$ & \\
\hline & $10-19$ & $50.7(45.7-55.7)$ & $19.0(15.8-22.8)$ & $30.2(26.1-34.7)$ & \\
\hline & $\geq 20$ & $29.8(23.7-36.8)$ & $15.1(11.2-20.1)$ & $55.1(48.0-62.0)$ & \\
\hline
\end{tabular}

* The percentage and confidence interval denotes column $\% .{ }^{\dagger}$ The number in parenthesis denotes column $\%$. SE: Standard error; CI: Confidence interval.

\subsection{Reasons for E-Cigarette Use and Frequency of E-Cigarette Use}

Among ever e-cigarette users, the most common reason for e-cigarette use was curiosity $(22.9 \%)$, followed by the belief that they were less harmful than conventional cigarettes $(18.9 \%)$, the desire to quit smoking $(13.1 \%)$, and the desire to smoke indoors (10.7\%) (Table 3). For infrequent e-cigarette users ( $<3$ per month), curiosity was the most frequent reason for e-cigarette use $(28.8 \%)$, whereas for more frequent e-cigarette users ( $>10$ per month), the desire to quit smoking $(21.0 \%)$ and the capacity for indoor use (19.5\%) were the most frequent reasons for e-cigarette use. The belief that e-cigarettes are less harmful was a common reason for use among both less ( $<3$ per month) and more $(\geq 10$ per month) frequent users of e-cigarettes $(19.3 \%$ and $17.9 \%$, respectively). 
Table 3. Frequency of e-cigarette use according to reason for e-cigarette use among ever e-cigarette users of Korean adolescents $(N=6656)$.

\begin{tabular}{|c|c|c|c|c|c|}
\hline \multirow{2}{*}{ Reason for E-Cigarette Use } & \multicolumn{5}{|c|}{ Number of Days Used E-Cigarettes, $\%(95 \% \mathrm{CI}) *$} \\
\hline & $N(\%){ }^{\dagger}$ & $0-2$ & $3-9$ & $\geq \mathbf{1 0}$ & \multirow{2}{*}{$p$-Value } \\
\hline$N(\%) \ddagger$ & $6656(100)$ & $4962(73.7)$ & $669(10.2)$ & 1024 (16.1) & \\
\hline Since they might be less harmful & $1254(18.9)$ & $19.3(18.0-20.7)$ & $17.9(15.1-21.0)$ & $17.6(15.3-20.1)$ & $<0.001$ \\
\hline For smoking cession & $851(13.1)$ & $10.6(9.5-11.7)$ & $18.7(15.6-22.2)$ & $21.0(18.1-24.3)$ & \\
\hline For indoor use & $675(10.7)$ & $7.9(7.2-8.7)$ & $17.0(14.0-20.3)$ & $19.5(17.0-22.3)$ & \\
\hline Since they are easily obtained & $94(1.5)$ & $0.6(0.4-0.9)$ & $5.2(3.6-7.5)$ & $3.0(2.1-4.3)$ & \\
\hline Since they have better taste & $658(9.6)$ & $9.0(8.1-10.0)$ & $12.6(10.2-15.6)$ & $10.5(8.6-12.8)$ & \\
\hline Since they have good flavor & $613(9.3)$ & $10.0(9.1-10.9)$ & $7.2(5.4-9.7)$ & $7.2(5.6-9.1)$ & \\
\hline Since they do not have the smoking smell & $491(7.5)$ & $6.4(5.7-7.2)$ & $7.5(5.5-10.2)$ & $12.5(10.4-15.0)$ & \\
\hline Curiosity & $1572(22.9)$ & $28.8(27.3-30.4)$ & $10.2(7.8-13.1)$ & $3.9(2.9-5.4)$ & \\
\hline Other & $447(6.6)$ & $7.4(6.6-8.2)$ & $3.7(2.4-5.6)$ & $4.7(3.5-6.4)$ & \\
\hline
\end{tabular}

${ }^{*}$ The percentage and confidence interval denotes row $\% .{ }^{\dagger}$ The number in parenthesis denotes row $\% .{ }^{\ddagger}$ The number in parenthesis denotes column \%. CI: Confidence interval.

\section{Discussion}

This study, similar to previous studies $[5,23,24]$, found that e-cigarette use was more prevalent among ever conventional cigarette smokers than among never conventional cigarette smokers. In addition, as the frequency and intensity of cigarette smoking increase, the percentage of frequent use of e-cigarette increases. This is different from the study conducted for U.S. adolescents, where the frequency e-cigarette use was not associated with the frequency and amount of conventional cigarette smoking [18]. This finding is plausible because even heavier adolescent smokers tend to be more nicotine-dependent [25] and would use e-cigarettes more heavily. It has been suggested that intensive or daily use of e-cigarettes, especially the tank type, may increase the chances of quitting smoking among adults [14,15]; however, no cessation aid, including e-cigarettes, has proved to be effective among adolescents [26]. Moreover, considering the potential adverse effect of nicotine on adolescent brain development [27], heavier e-cigarette use would likely cause more potential harm than benefit among adolescents.

In our study, most ever e-cigarette users were infrequent users. Even among daily smokers, more than $50 \%$ used e-cigarettes for $<3$ per month. This suggested that many adolescent e-cigarette users could be experimenters [17]. However, $9.5 \%$ of never smokers were frequent e-cigarette users ( $\geq 10$ per month), and 3.3\% were daily e-cigarette users. This means that non-smoking adolescents may be using e-cigarettes as new nicotine supplementary devices. This could be a serious issue because nicotine may delay brain development, causing problems with cognition and emotional regulation $[27,28]$, and e-cigarette use can be a gateway to combustible tobacco use and other substance use [8-10]. Also a recent study reported that the frequent e-cigarette vaping increased a risk of frequent and heavy conventional cigarette smoking 6 months later [29].

Overall, the most common reason for e-cigarette use was curiosity, followed by the belief that they are less harmful than conventional cigarettes, the desire to quit smoking, and the capacity for indoor use. The reasons for use differed according to the frequency of e-cigarette use. As expected, for frequent e-cigarette users, common reasons for use were the desire to reduce/quit smoking and the capacity for indoor use. This is worrisome because adolescents who use e-cigarettes as a method to avoid an indoor smoke-free policy may lose out on the chance of quitting smoking, which can interrupt a smoke-free policy. For infrequent e-cigarette users, curiosity, better taste, and good flavor comprised half of the reasons for e-cigarette use. This group initiates e-cigarette use for recreational purposes [30], and this can increase the probability of their becoming conventional cigarette smokers or other substance users [9]. 
Reasons for using e-cigarettes can be important in public health implications because they influence the continued use of e-cigarettes, and nicotine use is not safe especially among adolescents [10]. A previous study showed that adolescents who first tried to use e-cigarettes because they were cheap, because they wanted nicotine, or because they wanted to quit smoking tended to continue using e-cigarettes [19]. Additionally, adults who tried e-cigarettes for goal-oriented reasons (e.g., to use e-cigarettes where smoking was not allowed or to quit) were more likely to report continued use [31,32]. In our study, many e-cigarette users replied that they used e-cigarettes for the cessation of smoking. Additionally, we found that goal-oriented use of e-cigarettes (e.g., for smoking cessation, for indoor use, or because they were less harmful, had a better taste, or had less tobacco smell) were more prevalent among frequent users of e-cigarettes (e.g., $\geq 3$ per month). This can be a possible explanation for the association between reasons for use of e-cigarettes and the continued use of them. On the other hand, e-cigarettes can be used as a recreational device in terms of the purpose of e-cigarette uses, even in non-smoking adolescents [30]. Our findings show e-cigarettes were used as a smoking cessation aid among adolescent smokers and for recreational purposes even among non-smokers, although there is lack of evidence for their safety and efficacy in adolescents [26,27]. Therefore, we suggest the need for more education for adolescents about e-cigarettes and stricter control by the government.

Our study has several limitations. First, we could not establish any causal relations between the frequency of e-cigarette use and smoking frequency or intensity because our analysis was cross-sectional and the directionality of our findings could not be determined. Second, self-reports of e-cigarette use and smoking may differ from the actual rates. This is particularly true for smoking behavior among women, which may have been under-reported. Third, we could not evaluate why participants did not use e-cigarettes, especially among conventional cigarette only users. However, when we compared conventional cigarette only users with dual users of conventional cigarettes and e-cigarettes, dual users showed a significantly higher frequency and intensity of conventional cigarette smoking (Supplementary Table S1). Finally, we did not adjust the confounding variables to evaluate the frequency of e-cigarette use according to smoking behaviors or the reasons for e-cigarette use. Despite these limitations, however, this study has the advantage of using a large amount of nationally representative data. Our results can help in understanding the behaviors of adolescent e-cigarette users and may be usefully adopted in a future campaign to prevent adolescents from using e-cigarettes.

\section{Conclusions}

In conclusion, the frequency of e-cigarette use was positively associated with the frequency or intensity of conventional cigarette smoking. In terms of the reasons for e-cigarette use, curiosity was the most frequent reason among less frequent e-cigarette users, whereas the desire to quit smoking and the capacity for indoor use were more frequent reasons among frequent e-cigarette users. With the rapidly increasing prevalence of e-cigarette use among adolescents, this study can further our understanding of behaviors related to e-cigarette use and aid in the appropriate control of e-cigarettes.

Supplementary Materials: The following are available online at www.mdpi.com/1660-4601/14/3/305/s1. Table S1. Comparison between cigarette only users and dual users.

Author Contributions: Jung-Ah Lee wrote the original draft, reviewed the data, and performed statistical analysis; Sungkyu Lee wrote the original draft and critically reviewed the final manuscript; Hong-Jun Cho conceived and coordinated the study, reviewed the data, wrote the original draft, and critically reviewed the final manuscript.

Conflicts of Interest: The authors declare no conflict of interest.

\section{References}

1. Grana, R.; Benowitz, N.; Glantz, S.A. E-cigarettes: A scientific review. Circulation 2014, 129, $1972-1986$. [CrossRef] [PubMed]

2. Lee, S.; Kimm, H.; Yun, J.E.; Jee, S.H. Public health challenges of electronic cigarettes in South Korea. J. Prev. Med. Public Health 2011, 44, 235-241. [CrossRef] [PubMed] 
3. Dutra, L.M.; Glantz, S.A. Electronic cigarettes and conventional cigarette use among U.S. Adolescents: A cross-sectional study. JAMA Pediatr. 2014, 168, 610-617. [CrossRef] [PubMed]

4. White, J.; Li, J.; Newcombe, R.; Walton, D. Tripling use of electronic cigarettes among New Zealand adolescents between 2012 and 2014. J. Adolesc. Health 2015, 56, 522-528. [CrossRef] [PubMed]

5. Lee, S.; Grana, R.A.; Glantz, S.A. Electronic cigarette use among korean adolescents: A cross-sectional study of market penetration, dual use, and relationship to quit attempts and former smoking. J. Adolesc. Health 2014, 54, 684-690. [CrossRef] [PubMed]

6. Goniewicz, M.L.; Gawron, M.; Nadolska, J.; Balwicki, L.; Sobczak, A. Rise in electronic cigarette use among adolescents in Poland. J. Adolesc. Health 2014, 55, 713-715. [CrossRef] [PubMed]

7. Arrazola, R.A.; Singh, T.; Corey, C.G.; Husten, C.G.; Neff, L.J.; Apelberg, B.J.; Bunnell, R.E.; Choiniere, C.J.; King, B.A.; Cox, S.; et al. Tobacco use among middle and high school students-United States, 2011-2014. Morb. Mortal. Wkly. Rep. 2015, 64, 381-385.

8. Leventhal, A.M.; Strong, D.R.; Kirkpatrick, M.G.; Unger, J.B.; Sussman, S.; Riggs, N.R.; Stone, M.D.; Khoddam, R.; Samet, J.M.; Audrain-McGovern, J. Association of electronic cigarette use with initiation of combustible tobacco product smoking in early adolescence. JAMA 2015, 314, 700-707. [CrossRef] [PubMed]

9. Primack, B.A.; Soneji, S.; Stoolmiller, M.; Fine, M.J.; Sargent, J.D. Progression to traditional cigarette smoking after electronic cigarette use among U.S. adolescents and young adults. JAMA Pediatr. 2015, 169, 1018-1023. [CrossRef] [PubMed]

10. Wills, T.A.; Knight, R.; Sargent, J.D.; Gibbons, F.X.; Pagano, I.; Williams, R.J. Longitudinal study of e-cigarette use and onset of cigarette smoking among high school students in Hawaii. Tob. Control 2016. [CrossRef] [PubMed]

11. Barrington-Trimis, J.L.; Urman, R.; Berhane, K.; Unger, J.B.; Cruz, T.B.; Pentz, M.A.; Samet, J.M.; Leventhal, A.M.; McConnell, R. E-cigarettes and future cigarette use. Pediatrics 2016, 138, e20160379. [CrossRef] [PubMed]

12. Gmel, G.; Baggio, S.; Mohler-Kuo, M.; Daeppen, J.B.; Studer, J. E-cigarette use in young Swiss men: Is vaping an effective way of reducing or quitting smoking? Swiss. Med. Wkly. 2016, 146, w14271. [CrossRef] [PubMed]

13. Amato, M.S.; Boyle, R.G.; Levy, D. How to define e-cigarette prevalence? Finding clues in the use frequency distribution. Tob. Control 2016, 25, e24-e29. [CrossRef] [PubMed]

14. Biener, L.; Hargraves, J.L. A longitudinal study of electronic cigarette use among a population-based sample of adult smokers: Association with smoking cessation and motivation to quit. Nicotine Tob. Res. 2015, 17, 127-133. [CrossRef] [PubMed]

15. Brose, L.S.; Hitchman, S.C.; Brown, J.; West, R.; McNeill, A. Is the use of electronic cigarettes while smoking associated with smoking cessation attempts, cessation and reduced cigarette consumption? A survey with a 1-year follow-up. Addiction 2015, 110, 1160-1168. [CrossRef] [PubMed]

16. Delnevo, C.D.; Giovenco, D.P.; Steinberg, M.B.; Villanti, A.C.; Pearson, J.L.; Niaura, R.S.; Abrams, D.B. Patterns of electronic cigarette use among adults in the United States. Nicotine Tob. Res. 2016, 18, 715-719. [CrossRef] [PubMed]

17. Bauld, L.; MacKintosh, A.M.; Ford, A.; McNeill, A. E-cigarette uptake amongst UK youth: Experimentation, but little or no regular use in nonsmokers. Nicotine Tob. Res. 2016, 18, 102-103. [CrossRef] [PubMed]

18. Warner, K.E. Frequency of e-cigarette use and cigarette smoking by American students in 2014. Am. J. Prev. Med. 2016, 51, 179-184. [CrossRef] [PubMed]

19. Bold, K.W.; Kong, G.; Cavallo, D.A.; Camenga, D.R.; Krishnan-Sarin, S. Reasons for trying e-cigarettes and risk of continued use. Pediatrics 2016, 138, e20160895. [CrossRef] [PubMed]

20. Vickerman, K.A.; Schauer, G.L.; Malarcher, A.M.; Zhang, L.; Mowery, P.; Nash, C.M. Reasons for electronic nicotine delivery system use and smoking abstinence at 6 months: A descriptive study of callers to employer and health plan-sponsored quitlines. Tob. Control 2016. [CrossRef] [PubMed]

21. Kong, G.; Morean, M.E.; Cavallo, D.A.; Camenga, D.R.; Krishnan-Sarin, S. Reasons for electronic cigarette experimentation and discontinuation among adolescents and young adults. Nicotine Tob. Res. 2015, 17, 847-854. [CrossRef] [PubMed]

22. Kim, Y.; Choi, S.; Chun, C.; Park, S.; Khang, Y.H.; Oh, K. Data resource profile: The Korea youth risk behavior web-based survey (KYRBS). Int. J. Epidemiol. 2016, 45. [CrossRef] [PubMed]

23. Lee, J.A.; Kim, S.H.; Cho, H.J. Electronic cigarette use among Korean adults. Int. J. Public Health 2016, 61, 151-157. [CrossRef] [PubMed] 
24. Li, J.; Newcombe, R.; Walton, D. The prevalence, correlates and reasons for using electronic cigarettes among New Zealand adults. Addict. Behav. 2015, 45, 245-251. [CrossRef] [PubMed]

25. Zhan, W.; Dierker, L.C.; Rose, J.S.; Selya, A.; Mermelstein, R.J. The natural course of nicotine dependence symptoms among adolescent smokers. Nicotine Tob. Res. 2012, 14, 1445-1452. [CrossRef] [PubMed]

26. King, J.L.; Pomeranz, J.L.; Merten, J.W. A systematic review and meta-evaluation of adolescent smoking cessation interventions that utilized nicotine replacement therapy. Addict. Behav. 2016, 52, 39-45. [CrossRef] [PubMed]

27. England, L.J.; Bunnell, R.E.; Pechacek, T.F.; Tong, V.T.; McAfee, T.A. Nicotine and the developing human: A neglected element in the electronic cigarette debate. Am. J. Preve. Med. 2015, 49, 286-293. [CrossRef] [PubMed]

28. Counotte, D.S.; Smit, A.B.; Pattij, T.; Spijker, S. Development of the motivational system during adolescence, and its sensitivity to disruption by nicotine. Dev. Cogn. Neurosci. 2011, 1, 430-443. [CrossRef] [PubMed]

29. Leventhal, A.M.; Stone, M.D.; Andrabi, N.; Barrington-Trimis, J.; Strong, D.R.; Sussman, S.; Audrain-McGovern, J. Association of e-cigarette vaping and progression to heavier patterns of cigarette smoking. JAMA 2016, 316, 1918-1920. [CrossRef] [PubMed]

30. Pokhrel, P.; Herzog, T.A.; Muranaka, N.; Fagan, P. Young adult e-cigarette users' reasons for liking and not liking e-cigarettes: A qualitative study. Psychol. Health 2015, 30, 1450-1469. [CrossRef] [PubMed]

31. Pepper, J.K.; Ribisl, K.M.; Emery, S.L.; Brewer, N.T. Reasons for starting and stopping electronic cigarette use. Int. J. Environ. Res. Public Health 2014, 11, 10345-10361. [CrossRef] [PubMed]

32. Filippidis, F.T.; Laverty, A.A.; Gerovasili, V.; Vardavas, C.I. Two-year trends and predictors of e-cigarette use in 27 European Union Member States. Tob. Control 2016, 26, 98-104. [CrossRef] [PubMed]

(C) 2017 by the authors. Licensee MDPI, Basel, Switzerland. This article is an open access article distributed under the terms and conditions of the Creative Commons Attribution (CC BY) license (http:/ / creativecommons.org/licenses/by/4.0/). 